\title{
The regulation of GH secretion by sex steroids
}

\author{
Julie A Chowen, Laura M Frago and Jesús Argente \\ Department of Endocrinology, Laboratory of Investigation, Hospital Infantil Universitario Niño Jesús, Universidad Autónoma de Madrid, Madrid, Spain \\ (Correspondence should be addressed to J A Chowen, Department of Endocrinology, Hospital Infantil Universitario Niño Jesús, Avenida Menéndez Pelayo \\ 65, 28009 Madrid, Spain; Email: jachowen@telefonica.net)
}

\begin{abstract}
Gonadal sex steroids modulate GH synthesis and secretion with effects on both the hypothalamus and anterior pituitary. In the post-pubertal animal, androgens and oestrogens modulate hypothalamic somatostatin (SS) and GHRH synthesis respectively. These effects may be direct as SS neurons express the androgen receptor and many GHRH neurons are oestrogen receptor positive. The neonatal steroid environment modulates the number of GHRH neurons in the adult hypothalamus, as well as their responsivity to post-pubertal steroids. Furthermore, both neonatal and post-pubertal steroids modulate hypothalamic synaptic organisation affecting the number of synaptic inputs and the morphology of glial cells. This in turn has important effects on the ability of the hypothalamus to drive the secretory pulsatility of anterior pituitary hormone release. At the level of the somatotroph, androgens and oestrogens have been reported to stimulate, inhibit or have no effect on GH synthesis. In primary cultures, we found no effect of either androgens or oestrogens on GH mRNA levels. However, the sex steroid environment significantly modified the response of somatotrophs to SS. Furthermore, males have more somatotrophs compared with female rats and this partially depends on the neonatal sex steroid environment. In conclusion, sex steroids have both organisational and activational effects on the GH axis. These effects range from modulating the number of hypothalamic neurons controlling GH secretion, their responsiveness to later steroids, and the synaptic connectivity and neuropeptide production, to modulation of somatotroph numbers in the anterior pituitary and their responsiveness to inputs controlling $\mathrm{GH}$ synthesis and secretion.
\end{abstract}

European Journal of Endocrinology 151 U95-U100

\section{Introduction}

Sex steroids modulate systemic growth at numerous physiological levels and target sites, including direct actions at the hypothalamic and pituitary levels to modulate growth hormone $(\mathrm{GH})$ production and secretion, actions on the responsiveness of target tissue via modulation of receptor expression or intracellular signalling mechanisms and interactions with growth factors at both the cellular and intercellular levels. These diverse actions may contribute to some of the controversies that exist in the literature regarding the role of sex steroids in the control of systemic growth.

In both humans and experimental animal models the effects of sex steroids on systemic growth are most obvious during puberty, as the pubertal growth spurt is associated with a rise in sex steroids in both males and females. In the laboratory rat, the pubertal period is also associated with sexually dimorphic changes in the pattern of GH secretion that are directly associated with the difference in growth rate that exists between the sexes. Indeed, after the onset of puberty, male rats exhibit a GH secretory pattern consisting of higher more regular pulses superimposed on a low baseline level and begin to grow significantly faster compared with females $(1-3)$. Although the pubertal rise in sex steroids is fundamental for attainment of a normal pubertal growth spurt in both sexes, exposure to sex steroids during the neonatal period is also required $(2,3)$. These early permanent effects are often referred to as 'organisational', while reversible effects are termed 'activational', with both the hypothalamus and pituitary being involved.

Although sex steroids modulate systemic growth at the level of many target tissues, such as bone, cartilage or muscle $(4-6)$, these effects are beyond the scope of this review. We will discuss the regulation of $\mathrm{GH}$ secretion by sex steroids at the hypothalamic and pituitary level emphasizing the most basic elements involved in this system, the somatotroph and the somatostatin (SS) and GH-releasing hormone (GHRH) neurons.

\section{Sex steroid effects on the hypothalamus}

Sex steroids have both organisational and activational effects on SS and GHRH neurons, two neuropeptide systems directly involved in the control of GH synthesis and release from the anterior pituitary. Although SS is produced throughout the brain and hypothalamus, the neurons most directly involved in the control of $\mathrm{GH}$ secretion are located in the periventricular nucleus 
and are inhibitory to GH secretion and production. Normal adult males have higher mean SS mRNA levels per neuron in this nucleus compared with females $(7,8)$ and this higher inhibitory input has been suggested to be involved in producing the low nadir levels between GH secretory bursts in males. Likewise, GHRH neurons, located in the arcuate nucleus and medial hypothalamic area, have higher GHRH mRNA levels per neuron in males compared with females (8). This most likely underlies, at least in part, the higher $\mathrm{GH}$ production and secretion in male rats.

The number of GHRH mRNA containing neurons in the hypothalamus of male rats is significantly greater compared with that found in females, with no difference in the number of SS neurons in the periventricular nucleus (9). The differences between the sexes in the number of GHRH neurons, SS and GHRH mRNA levels and $\mathrm{GH}$ secretory pattern depend on exposure to sex steroids during both the neonatal and post-pubertal periods. Indeed, if a male rat is castrated on the day of birth, in adulthood his GH secretory pattern will be feminised $(2,3)$ and SS mRNA levels, GHRH mRNA levels and the number of GHRH neurons in the hypothalamus will be similar to that found in female rats (9). Similarly, if a female rat receives testosterone on the day of birth, the number of GHRH neurons in the adult brain increases significantly; however, there is no change in GHRH mRNA levels per cell (9). In contrast, while post-pubertal testosterone treatment has no effect on the number of GHRH neurons, it increase GHRH mRNA levels per cell and this effect is greater if the female was exposed to neonatal testosterone (9, see Fig. 1). This indicates that testosterone has organisational effects on the number of GHRH neurons and both organisational and activational effects on the ability of these neurons to respond to post-natal sex steroids. Although the number of SS neurons in the periventricular nucleus does not appear to be affected by testosterone during any developmental time frame, exposure to testosterone during both the neonatal and post-pubertal periods is necessary to achieve intact adult male SS mRNA levels (9, see Fig. 2).

Whether the neonatal organisational effects of testosterone on these two hypothalamic systems is mediated via the oestrogen or androgen receptor cannot be deduced from the above mentioned studies as only testosterone was employed. However, Simonian et al. (10) have demonstrated that the early organisational effects on the periventricular SS neurons are mediated through the oestrogen receptor, despite the fact that few or none of these neurons express the oestrogen receptor. This suggests that the effect may be mediated via another oestrogen responsive cell type. In vitro, sex steroid effects on hypothalamic neuron survival are also mediated via the oestrogen receptor (11), suggesting that the difference in GHRH neuron number could involve oestrogen-promoted neuronal survival. Indeed, the number of GHRH neurons in the

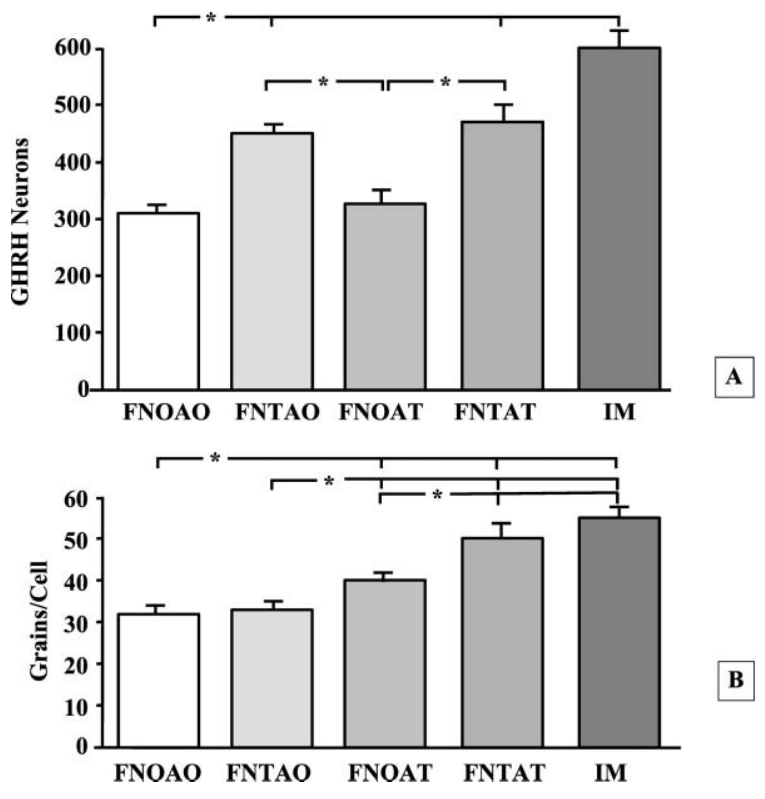

Figure $1(A)$ The mean number of GHRH neurons per area in the hypothalamus of adult rats. (B) Mean GHRH mRNA levels, as measured by in situ hybridisation and reported in grains per cell. FNOAO $=$ normal intact female rats, FNTAO $=$ female receiving neonatal testosterone (day 1 of life), FNOAT $=$ female receiving adult testosterone (Silastic capsule for 2 weeks), FNTAT = female receiving both neonatal and adult testosterone, $\mathrm{IM}=$ intact adult male. $n=6$ per group; error bars $=$ standard error. ${ }^{\star} P<0.05$ by ANOVA. Modified from Chowen et al. (9), with permission from The Endocrine Society, copyright 1993.

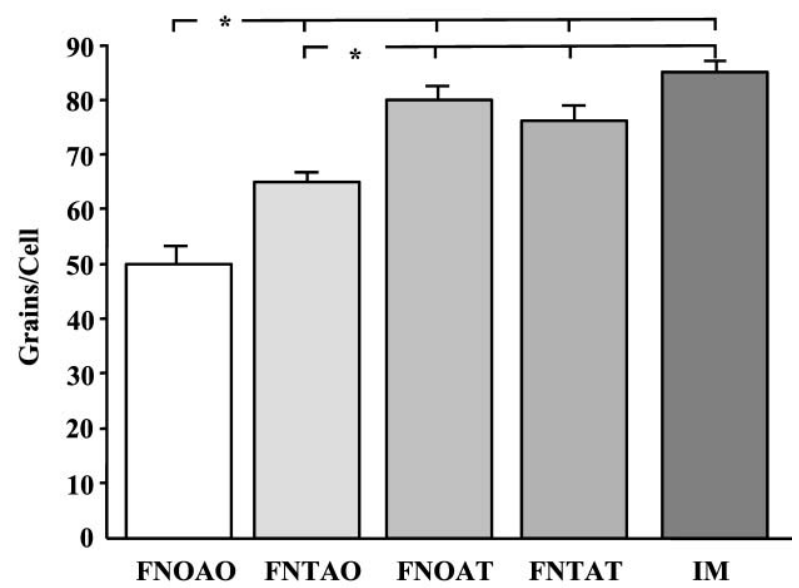

Figure 2 Mean SS mRNA levels, as measured by in situ hybridisation and reported in grains per cell, in the periventricular nucleus of adult rats. FNOAO = normal intact female rats, FNTAO = female receiving neonatal testosterone (day 1 of life), FNOAT = female receiving adult testosterone (Silastic capsule for 2 weeks), FNTAT $=$ female receiving both neonatal and adult testosterone, $\mathrm{IM}=$ intact adult male. $n=6$ per group; error bars = standard error. ${ }^{\star} P<0.05$ by ANOVA. Modified from Chowen et al. (9), with permission from The Endocrine Society, copyright 1993.

early neonatal period does not differ between male and female rats, but a progressive loss of neurons until approximately 20 days of age results in female rats having fewer of this neuron phenotype (J A Chowen, 
L M Frago \& J Argente, unpublished observations). However, whether this loss in GHRH neuron numbers is due to death of these neurons or a change in their phenotype remains to be determined.

In the adult male animal, the stimulatory effect of testosterone on SS mRNA levels is mediated via the androgen receptor (12). This effect is most likely direct as these neurons express the androgen receptor, with very few expressing the oestrogen receptor $(10,13)$. In contrast, the stimulatory effect of testosterone on GHRH mRNA levels is mediated through the oestrogen receptor (14). Indeed, these neurons have been shown to express the oestrogen receptor- $\alpha$ (15), but not androgen receptors (16). Hence, at the level of the hypothalamus there is a direct effect of sex steroids on the number of neurons involved in the control of $\mathrm{GH}$ secretion, as well as their neuropeptide synthesis.

Gonadal steroids are also involved in synaptic organisation and density in the hypothalamus, and this in turn modulates neuropeptide and neurotransmitter inputs to this area and outputs to structures such as the pituitary. Astroglia are thought to be involved in this modification of synaptic inputs in specific brain areas, including the hypothalamus, as these cells can change their morphology in response to oestradiol (17). In the arcuate nucleus, the area of the neuronal soma that is covered by glial processes is reported to be inversely proportional to the number of synaptic inputs (18). The number of axosomatic synapses in the arcuate nucleus is higher in female rats compared with males after 20 days of age and this depends on the neonatal steroid environment (19). Furthermore, in females the number of synapses varies throughout the oestrous cycle in response to the fluctuation in gonadal steroids (20). Exposure of females to testosterone on the day of birth abolishes this sex difference and the cyclic variation. Not only does the number of glial processes change in response to sex steroids, but also the expression of glial acidic fibrillary protein (GFAP), a specific glial marker and structural protein. Male rats have higher levels of GFAP in the arcuate nucleus and neonatal castration results in levels similar to that seen in females (21). Both neonatal and adult testosterone treatment of neonatal castrated males and normal females results in GFAP levels similar to that found in normal males (21). Hence, sex steroid effects on synaptic remodelling are mediated, at least in part, through actions on astroglia. These changes in synaptic inputs have been implicated in modifications in the pulsatile pattern of neuropeptide release and pituitary hormone secretory patterns.

\section{Sex steroid effects on the anterior pituitary}

Changes in circulating levels of sex steroids modulate the synthesis, content and secretion of $\mathrm{GH}$ from the anterior pituitary $(2,3,22,23)$, which could be due to a direct action of gonadal steroids on the somatotroph, or via modulation of the hypothalamic neuropeptides controlling GH secretion as mentioned above. Castration of adult male rats results in a significant decrease in GH mRNA levels and this decline is inhibited by testosterone replacement (22). However, in primary cultures, we found no effect of sex steroids on GH mRNA levels (22), which is in contrast to one report showing a slight increase in response to $17 \beta$-oestradiol (23). However, we have found that $17 \beta$-oestradiol reduced the inhibitory effect of SS on GH production, while having no effect on the stimulatory actions of GHRH (22). Hence, the response to oestrogens may depend on the surrounding hormonal environment. The oestrogen receptor is highly expressed in the anterior pituitary (24), suggesting the possibility of direct modulation of somatotrophs, or via modulation of neighbouring cells.

The number of GH-producing cells, or somatotrophs, is also affected by the neonatal sex steroid environment. The percentage of somatotrophs in the pituitary of normal adult male rats is significantly greater than that found in females $(25,26)$. Exposure of female rats to neonatal testosterone increases the number of somatotrophs in the adult pituitary, while adult testosterone has no significant effect (26, see Fig. 3A). In contrast, adult testosterone treatment increases $\mathrm{GH}$ mRNA levels per cell and neonatal testosterone exposure has no effect (26, see Fig. 3B). A similar effect is seen in male rats, where neonatal castration results in the percentage of somatotrophs in the adult pituitary being similar to that in the intact female; while adult castration has no significant affect on the number of somatotrophs, it significantly decreases the GH mRNA levels per cell (25). Interestingly, the inverse effect is seen on prolactin-producing cells, or lactotrophs.

Hence, the neonatal sex steroid environment has permanent effects on the cellular composition of the anterior pituitary and this partially determines the ability of this gland to produce and secrete specific hormones, including GH, throughout life. Whether these effects of sex steroids are mediated directly at the level of the pituitary remains to be determined. As hypothalamic factors are important in determining the cellular composition of the anterior pituitary $(27,28)$, modulation of these systems by neonatal steroids could also indirectly affect pituitary cell composition. Furthermore, whether these effects are oestrogen or androgen receptor dependent remains to be clarified. Disruption of the oestrogen receptor- $\alpha$ has been shown to result in an increase in $\mathrm{GH}$ production, indicating a negative effect of oestrogens (29). However, Yan et al. (30) have recently reported that somatotrophs of female aromatase knockout mice have decreased expression of GH, GH secretagogue 
(A)
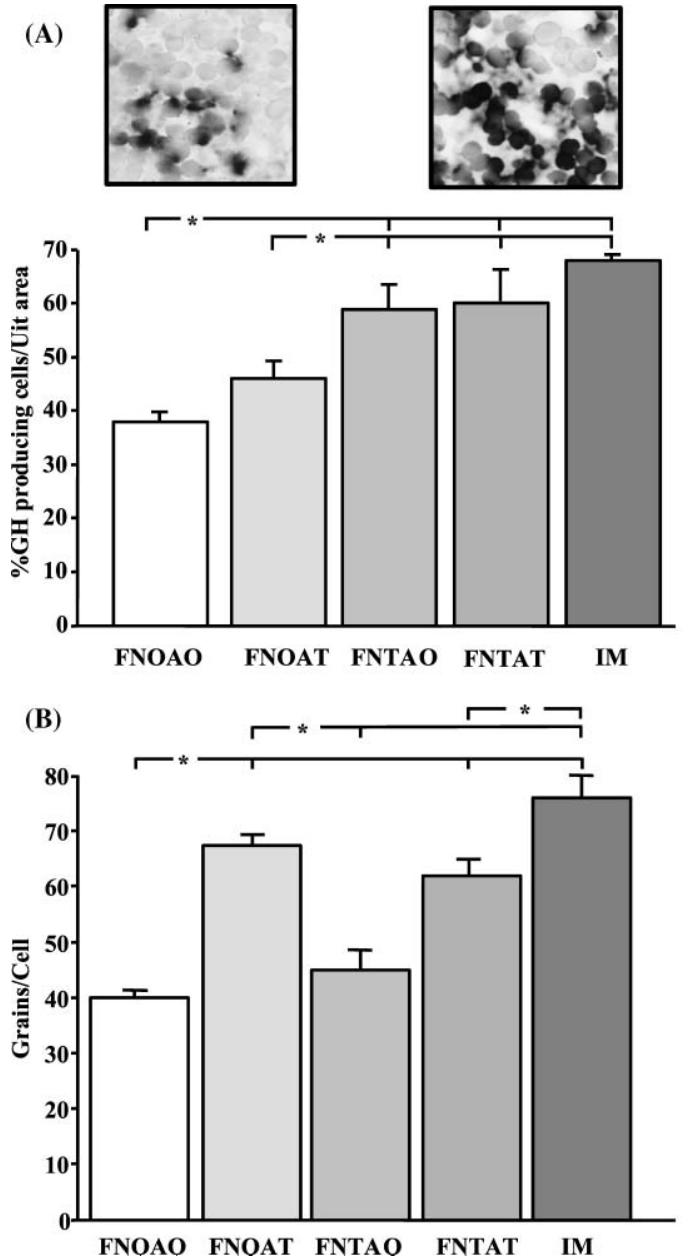

Figure 3 (A) Percentage of GH mRNA containing cells per unit area in the anterior pituitary of adult rats. The photographs are representative of a section through the pituitary of a normal female pituitary on the left and a male pituitary on the right labelled for GH mRNA. (B) Mean GH mRNA levels, as measured by in situ hybridisation and reported in grains per cell in adult rats. FNTAO = female receiving neonatal testosterone (day 1 of life), FNOAT = female receiving adult testosterone (Silastic capsule for 2 weeks), FNTAT $=$ female receiving both neonatal and adult testosterone, $\mathrm{IM}=$ intact adult male. $n=5$ per group; error bars = standard error, ${ }^{*} P<0.05$ by ANOVA. Modified from González-Parra et al. (26), with permission from The Society for Endocrinology.

receptor and GHRH receptor, while expression of SS receptors is elevated, although regulation of SS receptors by oestrogens may be subtype specific (31). Taken together, these studies emphasise the importance of oestrogens, and possibly androgens, on the development of the pituitary and somatotroph.

\section{Interaction of oestrogen with insulin-like} growth factor-I (IGF-I)

Many of the effects of $\mathrm{GH}$ on systemic growth are exerted through IGF-I. Furthermore, IGF-I is implicated in the development and maintenance of most tissues, including the hypothalamus and pituitary; thus, modulation of IGF-I by sex steroids will ultimately affect many of the actions of $\mathrm{GH}$. In recent years it has become apparent that in many tissues there is a close and complex relationship between sex steroids and growth factors and in particular between oestrogen and IGF-I (for reviews see 32-36). These interactions occur at various levels and are tissue dependent. For example, oestrogen modulates IGF-I, IGF-I receptor and IGF-binding protein levels, while IGF-I regulates steroid hormone synthesis and receptor levels. Moreover, IGF-I may activate the oestrogen receptor in the absence of sex steroids in different cell types and this is mediated by the Ras-Raf-mitogen-activated protein kinase cascade. Indeed, oestrogen and IGF-I have been shown to act through a common intracellular mechanisms in specific tissues and oestrogen may require the presence of IGF-I and/or the IGF-I receptor for its actions. As mentioned above, oestrogen modulates GFAP expression in the arcuate nucleus, but oestrogen activation of astrocytes is dependent on IGF-I receptors, although activation of IGF-I receptors alone is not sufficient to stimulate glial cells (37). Likewise, both oestrogens and IGF-I promote hypothalamic neuron survival, but these effects are not additive; in fact, these factors appear to act through a common mechanism depending on the activation of both the IGF-I and oestrogen receptors.

Hence, it is apparent that the study of 'sex steroid effects' on a tissue or system is becoming progressively more complex. The isolated effect of a hormone may not be similar when administered alone to that when administered in combination with other substances. The levels of interaction are various, with new possibilities being published continually. One interesting and active area of investigation of the effects of $\mathrm{GH}$ at the cellular level involves the suppressor of cytokine signalling (SOCS/CIS) family. These proteins are capable of inhibiting GH signalling by inhibition of the intracellular signal transducer STAT5 (38). Not only are SOCS proteins modulated by $\mathrm{GH}$ itself, but other hormones such as oestrogen (39) and vitamin D (40) can modulate GH effects through these proteins. Indeed, one mechanism by which oestrogens inhibit the effects of $\mathrm{GH}$ at the target tissue levels may involve SOCS proteins.

\section{Conclusion}

Sex steroids clearly modulate GH secretion through a variety of mechanisms, some of which we are most likely still unaware. There are direct effects on the neuropeptide systems controlling GH secretion, as SS and GHRH neurons express sex steroid receptors. However, there are also indirect effects, such as modifications in synaptic inputs. Furthermore, many studies 
have been performed in only one sex, while other studies suggest that the regulation of GH secretion may differ between the sexes. Indeed, at least the number of cells, including both hypothalamic neurons and somatotrophs, differs between males and females obviating the possibility in differential responses. Current areas of investigation involving interactions of hormones at the cellular and intracellular levels will undoubtedly add new dimensions to our understanding of not only sex steroid and GH interactions, but the interactions of many hormones on physiological growth.

\section{Acknowledgements}

This work was supported by grants from the Spanish Ministry of Science (SAF 2002-03324), the Community of Madrid (085/0002/2003) and the Fundación de Endocrinologia y Nutricion.

\section{References}

1 Edén S. Age- and sex-related differences in episodic growth hormone secretion in the rat. Endocrinology 1979105 555-560.

2 Jansson J-O, Edén S \& Isaksson O. Sexual dimorphism in the control of growth hormone secretion. Endocrine Reviews 19856 $128-150$.

3 Jansson J-O, Ekberg S, Isaksson OGP \& Edén S. Influence of gonadal steroids on age- and sex-related secretory patterns of growth hormone in the rat. Endocrinology $1984 \mathbf{1 1 4}$ 1287-1294.

4 Riggs BL, Khosla S \& Milton LJ III. Sex steroids and the construction and conservation of the adult skeleton. Endocrine Reviews $200223279-302$.

5 Brill KT, Weltman AL, Gentili A, Patrie JT, Fryburg DA, Hanks JB, Urban RJ \& Veldhuis JD. Single and combined effects of growth hormone and testosterone administration on measures of body composition, physical performance, mood, sexual function, bone turnover, and muscle gene expression in healthy older men. Journal of Clinical Endocrinology and Metabolism 200287 5649-5657.

6 Covol M, Blanchard O \& Tsagris L. Bone and cartilage responsiveness to sex steroid hormones. Journal of Steroid Biochemistry and Molecular Biology 199243 415-418.

7 Chowen-Breed J, Steiner RA \& Clifton DK. Sexual dimorphism and testosterone-dependent regulation of somatostatin gene expression in the periventricular nucleus of the rat hypothalamus. Endocrinology 1989125 357-362.

8 Argente J, Chowen JA, Zeitler P, Clifton DK \& Steiner RA. Sexual dimorphism of growth hormone-releasing hormone and somatostatin gene expression in the hypothalamus of the rat during development. Endocrinology 1991128 2369-2375.

9 Chowen JA, Argente J, González-Parra S \& García-Segura LM. Differential effects of the neonatal and adult sex steroid environments on the organization and activation of hypothalamic growth hormone-releasing hormone and somatostatin neurons. Endocrinology $19931332792-2802$.

10 Simonian SX, Murray HE, Gillies GE \& Herbison AE. Estrogendependent ontogeny of sex differences in somatostatin neurons of the hypothalamic periventricular nucleus. Endocrinology $19981391420-1428$.

11 Chowen JA, Torres-Aleman I \& García-Segura LM. Trophic effects of estradiol on fetal rat hypothalamic neurons. Neuroendocrinology $199256895-901$.
12 Argente J, Chowen-Breed J, Steiner RA \& Clifton DK. Somatostatin messenger RNA in hypothalamic neurons is increased by testosterone through activation of androgen receptors and not by aromatization to estradiol. Neuroendocrinology $1990 \quad \mathbf{5 2}$ 342-349.

13 Herbison AE. Sexually dimorphic expression of androgen receptor immunorectivity by somatostatin neurons in rat hypothalamic periventricular nucleus and bed nucleus of the stria terminalis. Journal of Neuroendocrinology $19957543-553$.

14 Zeitler P, Argente J, Chowen-Breed JA, Clifton DK \& Steiner RA. Growth hormone-releasing hormone messenger ribonucleic acid in the hypothalamus of the adult male rat is increased by testosterone. Endocrinology 1990127 1362-1368.

15 Kamegai J, Tamura H, Shimizu T, Ishii S, Sugihara H \& Wakabayashi I. Estrogen receptor (ER) alpha, but not ERbeta, gene is expressed in growth hormone-releasing hormone neurons of the male rat hypothalamus. Endocrinology $2001 \mathbf{1 4 2}$ 538-543.

16 Fodor M, Oudejans CB \& Delemarre-van de Waal HA. Absence of androgen receptor in the growth hormone releasing hormonecontaining neurones in the rat mediobasal hypothalamus. Journal of Neuroendocrinology 200113 724-727.

17 García-Segura LM, Torres-Aleman I \& Naftolin F. Astrocytic shape and glial fibrillary acidic protein immunoreactivity are modified by estradiol in primary rat hypothalamic cultures. Developmental Brain Research 198947 298-302.

18 García-Segura LM, Luquin S, Párducz A \& Naftolin F. Gonadal hormone regulation of glial fibrillary acidic protein immunoreactivity and glial ultrastructure in the rat neuroendocrine hypothalamus. Glia $1993 \mathbf{1 0} 59-69$

19 Pérez J, Naftolin F \& García-Segura LM. Sexual differentiation of synaptic connectivity and neuronal plasma membrane in the arcuate nucleus of the rat hypothalamus. Brain Research 1990 $\mathbf{5 2 7} 38-44$.

20 Olmos G, Naftolin F, Pérez J, Tranque PA \& García-Segura LM. Synaptic remodelling in the rat arcuate nucleus during the estrous cycle. Neuroscience 198932 663-667.

21 Chowen JA, Busiguina S \& García-Segura LM. Sexual dimorphism and sex steroid modulation of glial fibrillary acidic protein messenger RNA and immunoreactive levels in the rat hypothalamus. Neuroscience 199553 293-298.

22 González-Parra S, Chowen JA, García-Segura LM \& Argente J. In vivo and in vitro regulation of pituitary transcription factor-1 (Pit-1) by changes in the hormone environment. Neuroendocrinology $1996633-15$.

23 Martinoli MG, Veilleux R \& Pelletier G. Effects of triiodothyronine, dexamethasone and estradiol-17 $\beta$ on GH RNA in rat pituitary cells in culture as revealed by in situ hybridization. Acta Endocrinologica $1991 \mathbf{1 2 4} 83-90$.

24 Shupnik MA. Oestrogen receptors, receptor variants and oestrogen actions in the hypothalamic-pituitary axis. Journal of Neuroendocrinology $20021485-94$.

25 González-Parra S, Argente J, García-Segura LM \& Chowen JA. Cellular composition of the adult rat anterior pituitary is influenced by the neonatal sex steroid environment. Neuroendocrinology $1998 \mathbf{6 8} 152-162$.

26 González-Parra S, Argente J, García-Segura LM \& Chowen JA. Effect of neonatal and adult testosterone treatment on the cellular composition of the adult female rat anterior pituitary. Journal of Endocrinology $2000 \mathbf{1 6 4} 265-276$.

27 Chatelain A, Dupouy JP \& Dubois MP. Ontogenesis of cells producing polypeptide hormones (ACTH, MSH, LPH, GH and prolactin) in the fetal hypophysis of the rat: influence of the hypothalamus. Cell and Tissue Research 1979196 409-413.

28 Dean CE \& Porter TE. Regulation of somatotroph differentiation and growth hormone $(\mathrm{GH})$ secretion by corticosterone and GH-releasing hormone during embryonic development. Endocrinology $19991401104-1110$. 
29 Scully KM, Gleiberman AS, Lindzey J, Lubahn DB, Korach KS \& Rosenfeld MG. Role of estrogen receptor- $\alpha$ in the anterior pituitary gland. Molecular Endocrinology 199711 674-681.

30 Yan M, Jones ME, Hernandez M, Liu D, Simpson ER \& Chen C. Functional modification of pituitary somatotropes in the aromatase knockout mouse and the effect of estrogen replacement. Endocrinology 2004145 604-612.

31 Kimura N, Tomizawa S, Arai KN \& Kimura N. Chronic treatment with estrogen up-regulates expression of sst 2 messenger ribonucleic acid (mRNA) but down-regulates expression of sst5 mRNA in rat pituitaries. Endocrinology $19981391573-1580$.

32 Lee AV, Cui X \& Oesterreich S. Cross-talk among estrogen receptor, epidermal growth factor and insulin-like growth factor signaling in breast cancer. Clinical Cancer Research $200174429 \mathrm{~s}-4435 \mathrm{~s}$.

33 Cardona-Gomez GP, Menedez P, Don Carlos LL, Azcoitia I \& Garcia-Segura LM. Interactions of estrogen and insulin-like growth factor-I in the brain: molecular mechanisms and functional implications. Journal of Steroid Biochemistry and Molecular Biology $200283211-217$.

34 Clark PA \& Rogol AD. Growth hormones and sex steroid interactions at puberty. Endocrinology and Metabolism Clinics of North America 199625 665-681.

35 Garcia-Segura LM, Cardona-Gómez GP, Chowen JA \& Azcoita I. Insulin-like growth factor-I receptors and estrogen receptors interact in the promotion of neuronal survival and neuroprotection. Journal of Neurocytology 200029 425-437.
36 Chowen JA, Azcoitia I, Cardona-Gomez GP \& García-Segura LM. Sex steroids and the brain: lessons from animal studies. Journal of Pediatric Endocrinology and Metabolism 200013 1045-1066.

37 Fernandez-Galaz MC, Naftolin F \& Garcia-Segura LM. Phasic synaptic remodeling of the rat arcuate nucleus during the estrous cycle depends on insulin like growth factor-I receptor activation. Journal of Neuroscience Research 199955 286-292.

38 Ram PA \& Waxman DJ. SOCS/CIS protein inhibition of growth hormone-stimulated STAT5 signaling by multiple mechanisms. Journal of Biological Chemistry 1999274 35553-35561.

39 Leung KC, Doyle N, Ballesteros M, Sjogren K, Watts CKW, Low TH, Leona GM, Ross RJM \& Ho KKY. Estrogen inhibits GH signalling by suppressing GH-induced JAK2 phosphorylation, an effect mediated by SOCS-2. PNAS 2003100 1016-1021.

40 Morales O, Faulds MH, Lingren UJ \& Haldosen LA. 1Alpha,25-dihydroxyvitamin D3 inhibits GH-induced expression of SOCS-3 and CIS and prolongs growth hormone signaling via the Janus kinase (JAK2)/signal transducers and activators of transcription (STAT5) system in osteoblast-like cells. Journal of Biological Chemistry 2002277 34879-34884.

Received 18 May 2004

Accepted 5 August 2004 